\title{
The Reproductive Toxicity of Monosodium
}

\section{Glutamate by Damaging GnRH Neurons Cannot Be Relieved Spontaneously Over Time}

\author{
Cheng-Xiang Wang ${ }^{1, *}$ \\ Yue Zhang ${ }^{1} *$ \\ Qing-Feng $\mathrm{Li}^{2}$ \\ Hong-Liang Sun' \\ Hai-Ling Chong' \\ Jian-Xi Jiang' \\ Qing-Chun $\mathrm{Li}^{1}$
}

'Department of Reproductive Medicine, Binzhou Medical University Hospital, Binzhou, Shandong, People's Republic of China; ${ }^{2}$ Smart Gas Division, Qingdao iESLab Electronic Co., Ltd, Qingdao, Shandong, People's Republic of China

*These authors contributed equally to this work
Correspondence: Qing-Chun Li Department of Reproductive Medicine, Binzhou Medical University Hospital,

No. 66I Huanghe 2nd Road, Binzhou, 256603, People's Republic of China

Tel +86543325 8715

Fax +865433257792

Email qingchunli_doc@163.com
Objective: The present study aims to evaluate the effect of monosodium glutamate on testicular spermatogenesis in mice from the perspective of the hypothalamic-pituitarytesticular axis and whether this destructive effect is alleviated with time.

Methods: Neonatal mice were randomly divided into a monosodium glutamate (MSG) group and a control group, just below the interscapular region after birth with $10 \mu \mathrm{L}$ MSG to deliver $4 \mathrm{mg} / \mathrm{g}$ (body mass), or with equivalent volumes of $0.9 \%$ saline. Samples which involved blood, brains and testicles of mice were collected and measured at puberty at 60 days and adulthood at 90 days.

Results: The results show that the fluorescence intensity of GnRH nerve fibers, the levels of follicle-stimulating hormone (FSH), luteinizing hormone (LH), and testosterone (T) hormones in the reproductive system, the number of spermatocytes and spermatozoa in testicular sections, the body length, body weight, testicular weight, and testicular index in the 60-day-old mice in monosodium glutamate group (MSG60 group) and the MSG90 group were lower than those in the 60-day-old mice in normal control group (NC60 group) $(p<0.05)$, but the number of apoptotic cells in the testicular section was higher than in the NC60 group $(p<0.05)$. When the 90-day-old mice in monosodium glutamate group (MSG90 group) was compared with the MSG60 group, except for body weight and testicular weight increase $(p<0.05)$, there is no significant difference in the other parameters mentioned above $(p>0.05)$.

Conclusion: Monosodium glutamate can cause reproductive toxicity to male mice by damaging GnRH neurons, and this reproductive toxicity cannot be relieved spontaneously over time. These findings are supported by observed histological changes.

Keywords: monosodium glutamate, neurotoxicity, GnRH neurons, reproductive organs

\section{Introduction}

As the main component of food additives, ${ }^{1,2}$ monosodium glutamate (MSG) was first discovered by Japanese chemist Ju Miao Ikeda. ${ }^{3}$ Its main ingredient is L-glutamate sodium salt. Its free glutamate can stimulate human taste buds to produce delicious tastes, so it is widely used in cooking in Asia and West Africa. The dosage is not limited, and as a result, this food additive may be inadvertently abused. $^{4}$

In addition, glutamate (Glu) has the highest content of excitatory amino acids in the human and mammalian brain, which has potential neurotoxicity. ${ }^{5}$ MSG is absorbed in vivo and dissociates to glutamate at a physiological $\mathrm{pH}$ value, which has a strong polarity and is not easily passed through the blood-brain barrier (BBB) 
in theory, ${ }^{1}$ but the BBB function of newborn mammals is not perfect. ${ }^{6}$ Some pathological conditions, such as aging, ${ }^{7}$ nervous system diseases such as ischemic and hypoxic brain damage, Parkinson's disease, amyotrophic lateral sclerosis, Alzheimer's, and epilepsy, type 2 diabetes, ${ }^{8}$ and hypertension, ${ }^{9}$ can also increase BBB permeability, which elevates with increased plasma osmotic pressure. ${ }^{10}$ The increase in BBB permeability after administering certain drugs will allow all molecules to enter from the plasma, including Glu molecules. ${ }^{11}$ In these cases, Glu in the blood may cross the barrier and cause toxic effects even at physiological plasma levels. ${ }^{12}$

Neonatal animal experiments have reported that excess MSG has neurotoxicity, ${ }^{13}$ which is mainly confined to the arcuate nucleus of the retina and hypothalamus. It can lead to the destruction of dopamine and the cholinergic nodular funnel system in the arcuate nucleus-median eminence (Arc-ME) of the hypothalamus, leading to endocrine deficiency syndrome. ${ }^{14}$ GnRH neurons are mainly distributed in the median eminence of the hypothalamus and the medial part of the preoptic region. ${ }^{15,16}$ The release of GnRH is vital to the development of the reproductive system of mammals, causing the development of gonads by stimulating the release of FSH and $\mathrm{LH}$ in the pituitary. ${ }^{17-19}$ The development of BBB in young animals is not perfect. ${ }^{6}$ Glutamate is a neurotoxin. Exogenous administration of glutamate or sodium salt can pass through the BBB of neonatal animals, resulting in acute neurodegeneration and delayed death. ${ }^{20,21}$ It can selectively destroy the neuronal cell bodies of neonatal mice and other animals but has no significant effect on nerve fibers. $^{22,23}$

Many studies have shown that sodium glutamate is related to male infertility through the degeneration and change of the number and morphology of sperm cells. ${ }^{24,25}$ It may affect the reproductive development in newborn mice through the hypothalamus-pituitary-gonad axis, ${ }^{13,14,26}$ but this lacks direct histological evidence. For this reason, we designed an animal model using subcutaneous injections of MSG and sterilized water in neonatal mice, the objective of which was to compare the number of GnRH neurons, the levels of sex hormones, and the morphological data of testis in 60-day-old mice in monosodium glutamate group (MSG60 group), 60-day-old mice in normal control group (NC60 group) and 90-day-old mice in monosodium glutamate group (MSG90 group) to provide direct immunohistochemical evidence of the effect of sodium glutamate on the reproductive function of neonatal mice through the hypothalamus-pituitary-gonad axis and to explore whether this destructive effect can be cured spontaneously.

\section{Materials and Methods}

\section{Animals and Treatments}

Twelve female and six male Kunming mice, weighing 34.1 $\pm 3.2 \mathrm{~g}$, aged between eight and nine weeks old, were mated according to a female to male ratio of 2:1. The animals were obtained from Beijing Weitong Lihua Experimental Animal Technology Co., Ltd. All mice were maintained in a well-ventilated room under standardized conditions of a 12/12 light and dark cycle. They were given free access to standard feed pellets and drinking water. All animal experiments were carried out in accordance with the guidelines of Binzhou Medical University for animal care. The study was carried out in neonatal male Kunming mice and was conducted with approval from the Ethics Committee of Binzhou Medical University Hospital (No:2018-G005-01).

A total of 108 neonatal Kunming mice were randomly divided into monosodium glutamate 60-day-old group (MSG60), monosodium glutamate 90-day-old group (MSG90) and normal saline 60-day-old (NC60) group. Thirty-six neonatal Kunming mice of each group were subcutaneously injected into the dorsal dermis area, just below the interscapular region on days 1, 3, 5, 7 and 9 after birth with $10 \mu \mathrm{L}$ MSG (Sigma-Aldrich; Merck $\mathrm{KGaA}$, St. Louis, MO, USA) to deliver $4 \mathrm{mg} / \mathrm{g}$ (body mass), or with equivalent volumes of $0.9 \%$ saline. At four weeks of age, the male pups were weaned, sexed, and housed in groups according to treatment. Blood, brains and testicles of mice were collected and measured at 60 days at puberty (MSG60 group and NC60 group) and 90 days at adulthood (MSG90 group). All procedures on animals followed the guidelines for work on experimental animals approved by the Ethics Committee of the Faculty of Binzhou Medical University.

\section{Somatotype Measurement, Hormone Determination, and Tissue Acquisition}

Before the measurement and sampling, the animals fasted for 12 hours. The animals were lightly anesthetized with diethyl ether, their length and weight were measured, and orbital blood was taken to determine serum FSH, LH, and $\mathrm{T}$. The blood was collected in an EDTA tube containing 500 $\mathrm{kIU}$ aprotinin and centrifuged at $4^{\circ} \mathrm{C}$ in a frozen centrifuge 
at $3500 \mathrm{rpm}$ for $15 \mathrm{~min}$. The separated serum was stored at $-80^{\circ} \mathrm{C}$ until the determined time. All the blood, brains and testicles of mice from the same subject were run in duplicate in the same group, using a Mouse ELISA Kit (Shanghai Enzyme-linked Biotechnology Co., Ltd., China).

After euthanasia, the heart was dissected, the right atrial appendage was cut using ophthalmic scissors, and a perfusion needle was first quickly and then slowly injected into the left ventricle perfused with normal saline until the effluent became clear, and 4\% paraformaldehyde continued to be perfused until the tissue hardened. The brains were quickly dissected out and stored in $4 \%$ paraformaldehyde for 12 hours and was moved into a $30 \%$ sucrose solution for 72 hours and then a $40 \%$ sucrose solution and kept at $4^{\circ} \mathrm{C}$. The testes were fixed with $4 \%$ paraformaldehyde for 72 hours and then preserved with $75 \%$ alcohol.

\section{Immunofluorescence}

The mouse's entire brain was removed from the sucrose solution, and the cerebellum and forebrain were trimmed with a coronary knife, leaving only part of the thalamus, and the thickness of the section was cut to $40 \mu \mathrm{m}$. About 25 brain sections containing the cell bodies of $\mathrm{GnRH}$ neurons could be cut from the median eminence to the tail of the hypothalamus. Then, the cut sections were successively collected into five holes of a 6-hole plate containing 30\% glycerol, 30\% ethylene glycol, and $40 \%$ sucrose in a phosphate-buffered saline (PBS) ( $\mathrm{pH}$ 7.2) solution, and one group was randomly selected and sealed at room temperature for $1 \mathrm{~h}(0.3 \%$ TritonX-100, $0.25 \%$ bovine serum albumin (BSA), and 5\% normal goat serum (GS)). Sections were then placed on a shaker for $48 \mathrm{~h}$ at $4^{\circ} \mathrm{C}$, incubated with GnRH antibody (sc-32292, Santa Cruz Biotechnology, Inc.), and diluted in blocking solution at a dilution of 1:100. Next, sections were rinsed with a $0.01 \mathrm{M}$ PBS solution ( $\mathrm{pH}$ 7.2) three times and incubated for $60 \mathrm{~min}$ at room temperature with a second antibody (DyLight 649 E32610, Abbkine Scientific Co., Ltd., CA, USA), goat anti-mouse IgG, diluted in blocking solution, with a dilution of 1:5000, after avoiding light. Next, DAPI stain (sc-24941, Santa Cruz Biotechnology, Inc., USA) was applied for three minutes. Then, the sections were rinsed with $0.01 \mathrm{M}$ PBS solution $(\mathrm{pH} 7.2)$ three times and then pasted on the cationic anti-unloading glass slides and sealed with anti-fluorescence attenuation tablets.

The sections were observed using a Leica TCS SP5 II laser scanning confocal microscope (Leica Microsystems,
Inc., USA). After each section was stained by immunofluorescence, six visual fields were randomly selected from the same anatomical site and photographed under a 200x microscope. The brightness and contrast of the photos were optimized by Adobe Photoshop CS6 software, and the number of neurons was counted by Image-Pro Plus 6.0 software.

\section{Histological Study of Testis}

The testicles were rinsed in buffer saline after being fixed in $4 \%$ paraformaldehyde. They were dehydrated in a graded concentration of ethanol, removed with xylene, and then embedded in paraffin. The sections were then cut into $5 \mu \mathrm{m}$ thick slices, mounted to the glass slides, and were examined under an optical microscope. Then, the testicular tissue sections were stained with H\&E staining and TUNEL staining. Ten paraffin sections were randomly selected from each group, and five seminiferous tubules were randomly chosen in each section. Under a 400x microscope, the number of spermatogonia and spermatozoa in the H\&E sections and the number of apoptotic cells in the TUNEL sections was calculated by Image-Pro Plus 6.0 software. The excessive or omitted spermatogonia or spermatozoa were removed or added. The AI values of spermatogonia and spermatozoa in convoluted seminiferous tubules were calculated and scored according to the John score (JS), ${ }^{23}$ and the average number of apoptotic cells in each seminiferous tubule was calculated as the apoptotic index (AI).

\section{Statistical Analysis}

Data analysis was conducted using SPSS for Windows (version 26.0; SPSS Inc., Chicago, IL, USA). One-way analysis of variance (ANOVA) and post hoc Tukey's test were performed to determine the significant difference between groups. Results are presented as mean \pm SEM. Values were considered statistically significant if $p<0.05$.

\section{Results}

\section{Somatotype and Testicular Morphological Characteristics of Mice}

The evaluation of the MSG group with the control group revealed significant differences, such as dull hair, short and fat body composition, thick subcutaneous fat, short penis, atrophy of testicular diameter and volume, and the inability of the testis to descend into the scrotum (Figures 1 and 2). The body length, the average testicular diameter, the testicular weight, and the testicular index in both the MSG60 and the MSG90 groups were significantly lower than the NC60 


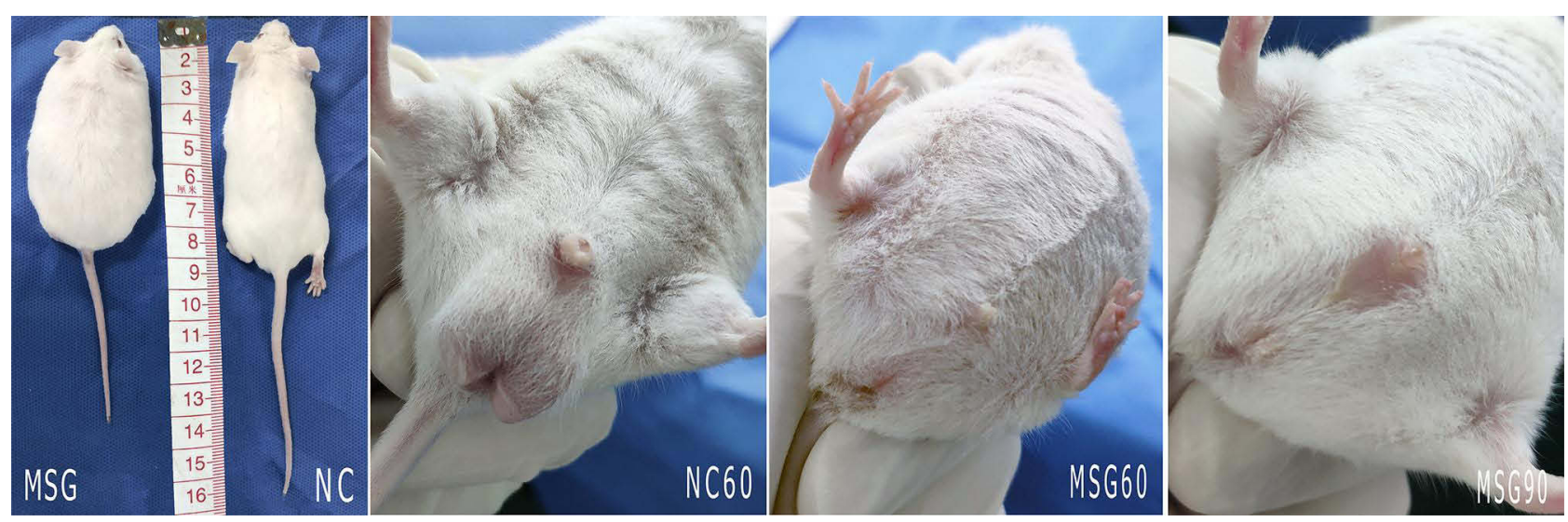

Figure I The mice in the monosodium glutamate group from the age of 60 days show significant changes differing from the control group, such as dull hair, short and fat body composition, thick subcutaneous fat, short penis, dysplasia of testis, and the inability of the testis to descend into the scrotum. This condition is still evident at the age of 90 days.

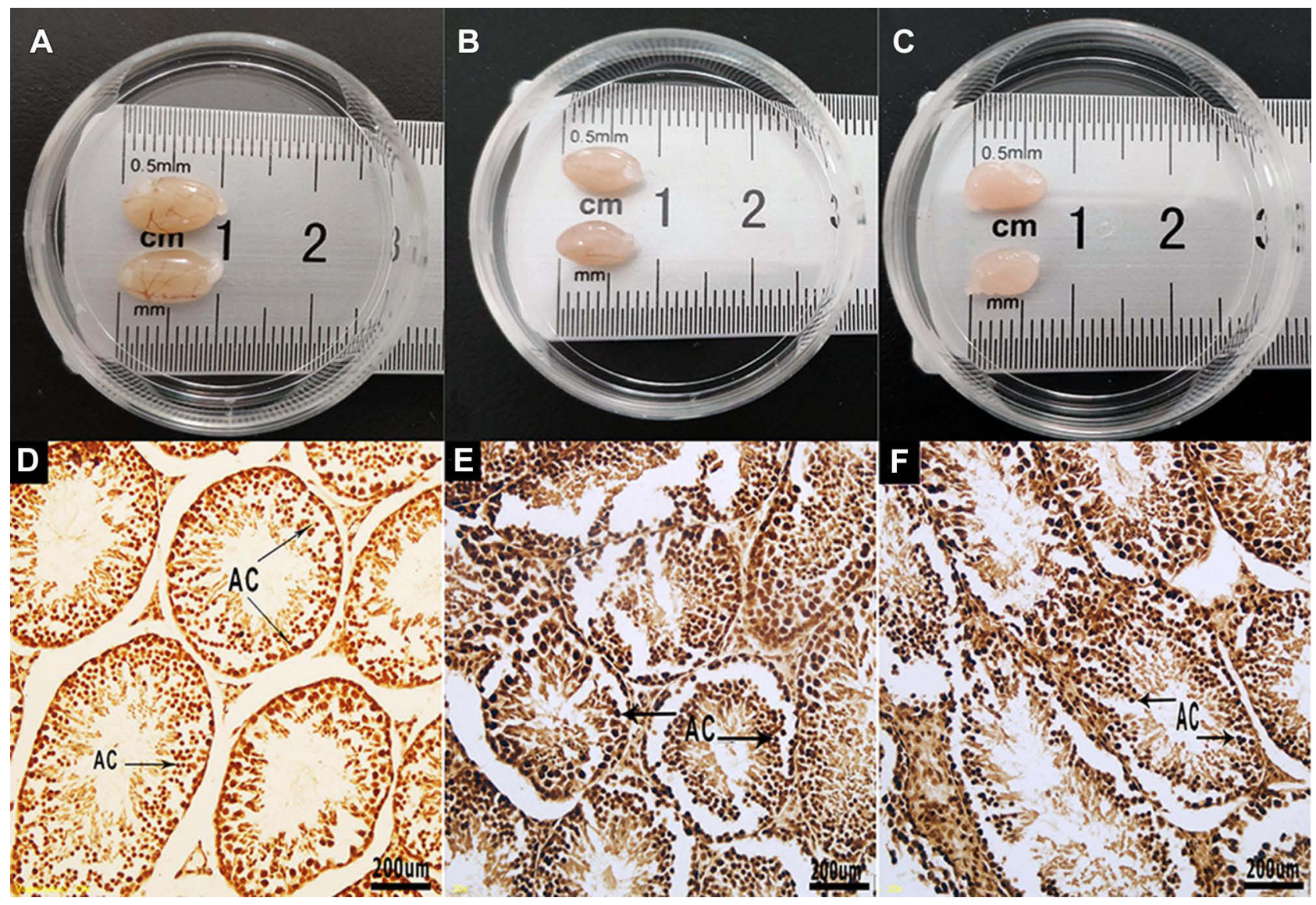

Figure 2 Testis and apoptotic staining of testicular sections. (A) Testes of the NC60 group. (B) Testes of the MSG60 group. (C) Testes of the MSG90 group. (D) Testis section of the NC60 group. A small number of apoptotic cells (AC) stained brown can be seen, XI00: bar, $200 \mu \mathrm{m}$. (E) Testis section of the MSG60 group. A large number of apoptotic cells (AC) stained brown can be seen, XI00. (F) Testis section of the MSG90 group. A large number of apoptotic cells (AC) stained brown can be seen, XI00.

group ( $p<0.05$; Table 1). In addition, we found the MSG90 group compared with the MSG60 group had a significant increase in body weight and testicular weight $(p<0.05)$, but the body length, the average testicular diameter, and the testis index had no significant difference $(p>0.05$; Table 1$)$.

\section{Neurotoxicity}

Immunofluorescence staining of frozen sections of the hypothalamus showed that MSG-treated mice had a significantly decreased immunofluorescence staining of GnRH-positive neuronal cell bodies and fibers of the 
Table I Body Length, Weight and Organ Weights. Values are Expressed as Means \pm SEM

\begin{tabular}{|l|c|c|c|}
\hline Variables & NC60 & MSG60 & MSG90 \\
\hline Body weight (g) & $34.12 \pm 5.01$ & $28.26 \pm 3.56^{\mathrm{a}}$ & $32.78 \pm 5.13^{\mathrm{ab}}$ \\
Testis weight (g) & $0.1920 \pm 0.0212$ & $0.0729 \pm 0.0258^{\mathrm{a}}$ & $0.0902 \pm 0.0117^{\mathrm{ab}}$ \\
Testicular index & $0.00463 \pm 0.00074$ & $0.00264 \pm 0.00105^{\mathrm{a}}$ & $0.00283 \pm 0.00060^{\mathrm{ac}}$ \\
Body length(cm) & $20.22 \pm 1.07$ & $16.06 \pm 0.59^{\mathrm{a}}$ & $16.57 \pm 1.04^{\mathrm{ac}}$ \\
Testicular long axis(cm) & $0.84 \pm 0.05369$ & $0.60 \pm 0.05743^{\mathrm{a}}$ & $0.64 \pm 0.05316^{\mathrm{ac}}$ \\
\hline
\end{tabular}

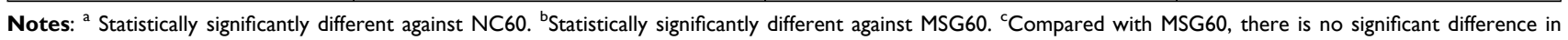
statistics.

arcuate nucleus (ARC). As a result, the fluorescence intensity of GnRH immunofluorescence positive neurons in the MSG60 and MSG90 groups were significantly less than in the NC60 group ( $p<0.05$; Figures 3 and 4 ). With the prolongation of time after MSG injection, the immunofluorescence intensity of GnRH immunofluorescent positive neurons and fibers in the MSG90 group was slightly stronger than in the MSG60 group, but there was no significant difference in the fluorescence intensity of GnRH immunofluorescence positive neurons between the MSG90 and MSG60 groups ( $p>0.05$; Figures 3 and 4).

\section{Reproductive Hormonal Assays}

Comparing the levels of FSH, LH, and T hormones between groups revealed a significant reduction in both the MSG60 and MSG90 groups compared with the NC60 group ( $p<0.05$; Figure 5). However, there was no significant difference in FSH, LH, and $\mathrm{T}$ hormone levels between the MSG90 and MSG60 groups $(p>0.05$; Figure 5).

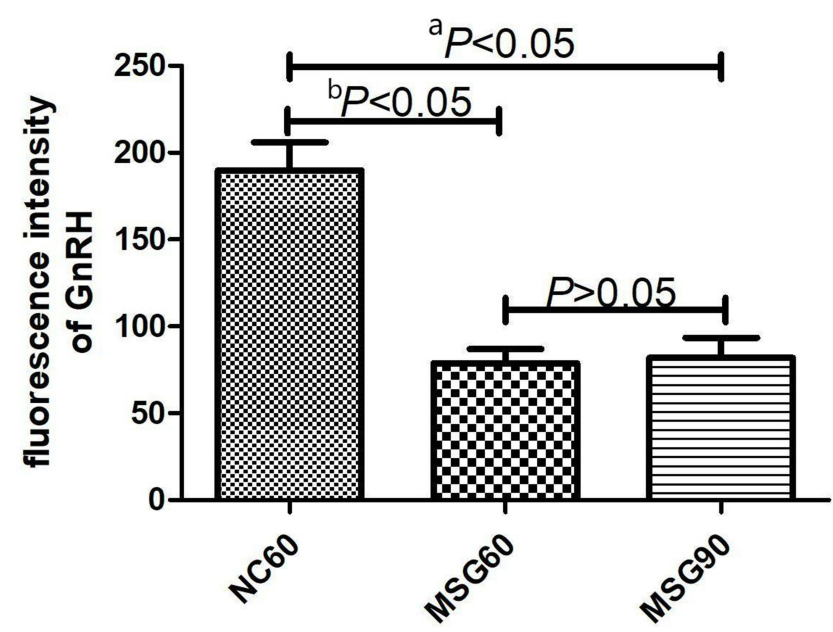

Figure 3 Effects of monosodium glutamate on the number of $\mathrm{GnRH}$ neurons. Comparison between the MSG60 group and the NC60 group $\left({ }^{a} p<0.05\right)$. Comparison between the MSG60 group and the MSG90 group $\left({ }^{b} p<0.05\right)$.

\section{Histological Observation Apoptosis Status Evaluation of Testis}

The apoptosis of mouse testicular sections stained by TUNEL is shown in Figure 2D-F. The average number of apoptotic cells in each seminiferous tubule was calculated as the AI. The number of apoptotic cells in the MSG60 and MSG90 groups was significantly higher than the NC60 group ( $p<0.05$; Figure 6B). However, the number of apoptotic cells in the MSG90 group was not statistically different from that in the MSG60 group $(p>0.05$; Figure 6B).

\section{Sperm Characteristics}

The H\&E staining of the testicular paraffin sections is shown in Figure 7. In the testicular section of the NC60 group, the seminiferous tubules at all levels were closely arranged, the structure was complete and clear, the seminiferous epithelium was thick, a large number of sperm cells and mature spermatozoa could be seen in the lumen, and intact sperm tails could be seen. The spermatogenic cells in the tube wall were mainly spermatogonia and spermatocytes with uniform staining and clear structures. A small number of exfoliated necrotic cells could be seen in some seminiferous tubules.

In the testicular sections of the MSG60 and MSG90 groups, the seminiferous tubules at all levels were arranged loosely and disorderly, the structure was not clear, the seminiferous epithelium was thin, the interstitial staining was unclear, part of the lumen was closed, the spermatozoa and mature spermatozoa were less produced in the lumen, the sperm tails were unclear, the spermatogenic cells in the tube wall were mainly spermatogonia and spermatocytes, the cytoplasmic staining was uneven, the cell structure was not clear, and more exfoliated and necrotic cells could be seen in the seminiferous tubules. The JS score, the average seminiferous cell, and total sperm count of each seminiferous tubule in the MSG60 and MSG90 groups were significantly lower than in the NC60 group ( $p<0.05$; Figure 6A and C), 


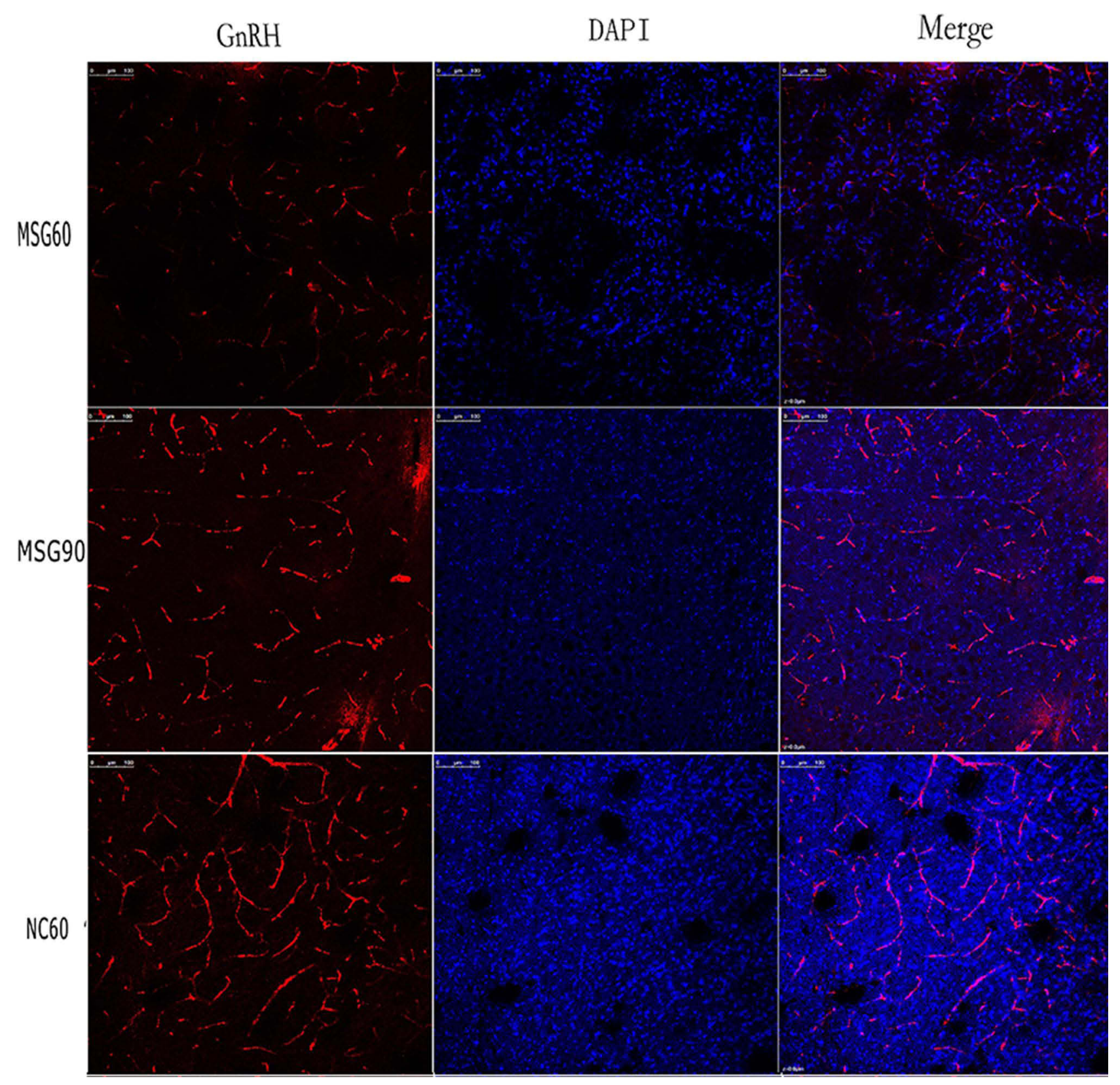

Figure 4 Effects of monosodium glutamate on GnRH neurons. The immunofluorescence intensity of immunofluorescent GnRH-positive neuronal cell bodies and fibers in both monosodium glutamate groups was weaker than in the control group. The number of immunofluorescent GnRH-positive neuronal cell bodies and fibers in the immunofluorescence staining group was significantly less than in the control group. The immunofluorescence intensity of the MSG90 group was slightly stronger than the MSG60 group. There was no significant difference in the number of immunofluorescent $\mathrm{GnRH}$-positive neuronal cell bodies and fibers: bar, I00 $\mu \mathrm{m}$.

but there was no significant difference in sperm count and JS score between the MSG90 and MSG60 groups $(p>0.05$; Figure $6 \mathrm{~A}$ and $\mathrm{C}$ ).

\section{Discussion}

Peroxisome proliferator-activated receptors (PPARs), a family of ligand-activated transcription factors, modulate the expression of many genes implicated in several diseases, such as obesity, type 2 diabetes (T2DM), dysipidemias and metabolic syndrome. ${ }^{27}$ Our study demonstrated that the mice of the MSG group represent the dull hair, short and fat body composition, thick subcutaneous fat, short penis, and so on. A study found that the PPAR $a / \gamma$ dual agonist chiglitazar might reduce the insulin resistance in the muscle of MSG obese rats ${ }^{28}$ The MSG obese mice may be related to PPARs desensitization.

A large number of animal experiments have shown that excessive MSG has neurotoxicity, ${ }^{20,29,30}$ which is mainly 

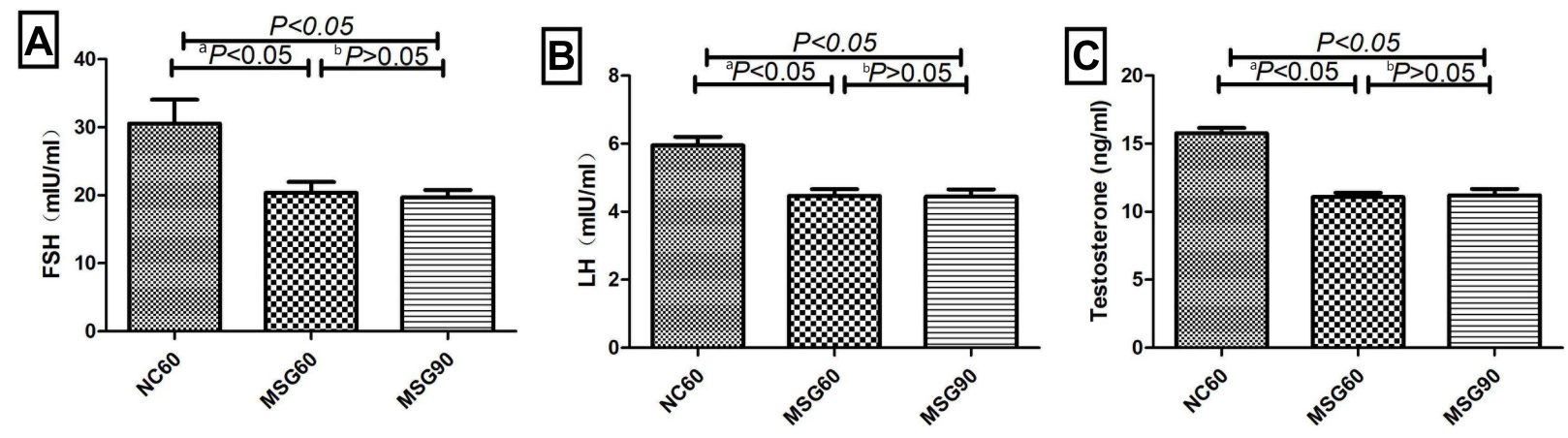

Figure 5 Effects of monosodium glutamate on the level of $(\mathbf{A})$ the follicle-stimulating hormone, $(\mathbf{B})$ luteinizing hormone, and $(\mathbf{C})$ testosterone. Comparison between the MSG60 group and the NC60 group $\left({ }^{a} p<0.05\right)$. Comparison between the MSG60 group and the MSG90 group $\left({ }^{b} p>0.05\right)$.
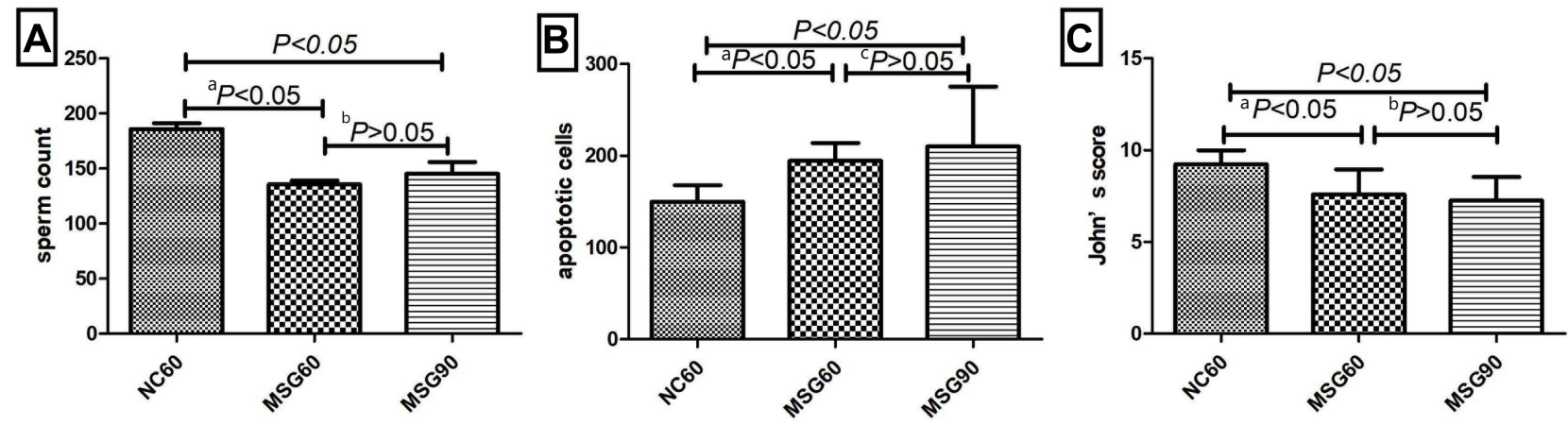

Figure 6 Effects of monosodium glutamate on sperm count (A), number of apoptotic cells (B), and John's score (C); comparison between the MSG60 group and the NC60 group $\left({ }^{\mathrm{a}} p<0.05\right)$; comparison between the MSG60 group and the MSG90 group ( $\left.{ }^{b} p>0.05\right)$; comparison between the MSG60 group and the MSG90 group $\left({ }^{c} p>0.05\right.$ ).

confined to the arcuate nucleus of the retina and hypothalamus, resulting in the destruction of the Arc-ME dopaminergic and cholinergic nodular funnel system in the hypothalamus, causing acute neurodegeneration and delayed death. ${ }^{21}$

There are two main types of Glu receptors in the nervous system: ionic and metabolic. Both receptors combine with Glu and cause postsynaptic membrane depolarization. ${ }^{31}$ The neurotoxic effect of excessive Glu mainly destroys the nerve cell body but has no significant effect on nerve fibers. The main mechanisms of neurotoxicity induced by Glu are as follows: (1) Glu acts on $\alpha$-amino-3-hydroxy-5-methyl-4-isoxazolepropionatic acid (AMDA) and kainic acid (KA) receptors on the cell membrane, which increases the permeability of $\mathrm{Na}^{+}$. A large influx of $\mathrm{Na}^{+}$changes the membrane potential, a large amount of potential difference of $\mathrm{Cl}^{-}$inflows, and a large amount of water inflow causes acute swelling of neurons; (2) Glu can act on the N-methyl-D-aspartate (NMDA) receptor on the cell membrane and increase the permeability of $\mathrm{Ca}^{2+} . \mathrm{Ca}^{2+}$ influx increases intracellular inositol triphosphate production through metabolic receptors, which stimulates endoplasmic reticulum $\mathrm{Ca}^{2+}$ release, activates phosphatase and protease, causes cell damage, causes a series of biochemical reactions, and finally leads to delayed neuronal necrosis. ${ }^{32,33}$ Excessive Glu causes extensive damage to most brain regions and does not specifically damage a particular nucleus of the brain. ${ }^{1}$ In this study, comparing the MSG groups with the normal saline control group, the MSG groups showed obvious limitation of growth, accumulation of subperitoneal fat, dysplasia of external genitalia and testis, and the appearance characteristics were the same as those found by Nemeroff et al. ${ }^{14}$

There was no significant change in the 90-day-old mice in the MSG group compared with the 60-day-old mice except for body weight. The possible reason is that MSG leads to the destruction of the hypothalamic Arc-ME dopaminergic and cholinergic nodular funnel system, leading to the emergence of "endocrine deficiency syndrome." By interfering with the hypothalamic signal cascade mediated by leptin, the energy balance is destroyed, resulting in individual growth retardation, obesity, physiological disorders of adipose tissue, hypogonadism, etc. ${ }^{6,20,34,35}$

GnRH neurons were mainly distributed in the median eminence of the hypothalamus and medial preoptic area. ${ }^{15}$ 


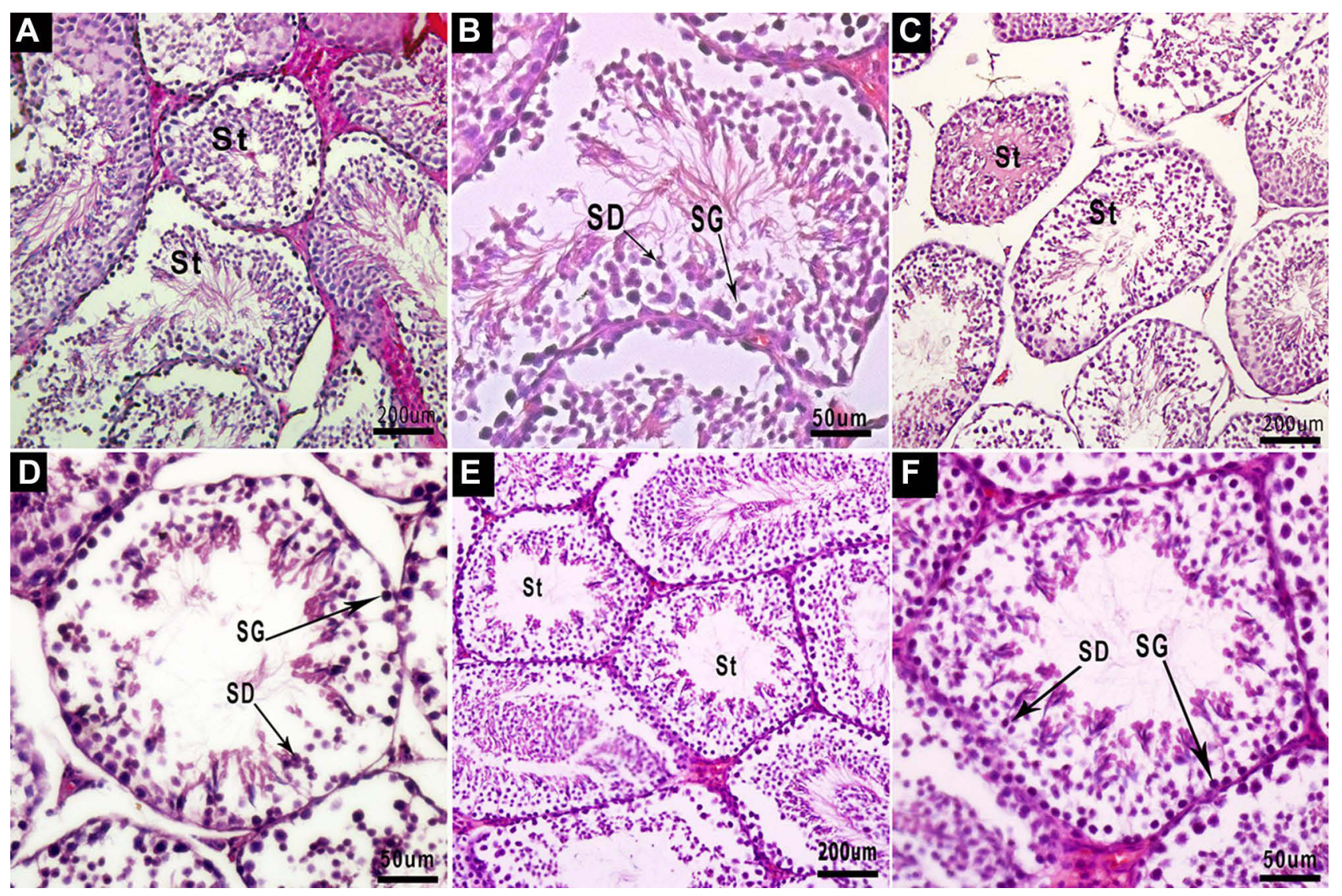

Figure 7 Testicular cross-sections of mice, stained with H\&E. (A) Testis section of the NC60 group, showing the normal histological structure of seminiferous tubules (St) containing spermatocytes and late spermatids in the lumen, XI00: bar, $200 \mu \mathrm{m}$. (B) At higher magnification, the seminiferous epithelium consisting of spermatogonia (SG), spermatocytes, and spermatids (SD) can be observed clearly, X400: bar, $50 \mu \mathrm{m}$. (C) Testis section of the MSG60 group. The arrangement of seminiferous tubules is loose and scattered, part of the lumen is closed, and the structure is unclear, XI00. (D) At higher magnification, the spermatogenic epithelium is thin, the interstitial staining is unclear, the production of sperm cells and mature sperm in the lumen is less, the tail of the sperm is unclear, the spermatogenic cells in the tube wall are mainly spermatogonia (SG) and spermatocytes, and the cytoplasmic staining is uneven, X400. (E) Testis section of the MSG90 group, X100, and higher magnification (F), X400. The structural morphology is the same as the MSG60 group: bar, $50 \mu \mathrm{m}$.

GnRH is vital for the development of the mammalian reproductive system. GnRH can promote gonadal development by stimulating the release of FSH and LH in the pituitary gland. ${ }^{36}$ In this study, the number of GnRH neurons and the levels of FSH, LH, and T hormones in the brain of the MSG60 group were significantly lower than the NC60 group. There was no significant difference in the number of GnRH neurons, FSH, LH, and $\mathrm{T}$ hormone levels between the MSG90 and MSG60 groups, indicating that MSG injections damaged GnRH neurons and caused a decrease in the level of corresponding hormones in neonatal mice. This damaging effect could not be alleviated naturally after the mice entered adulthood.

The decline in the weight of reproductive organs is an indicator of reproductive toxicity and may indicate tissue atrophy and degeneration. Testicular weight depends on the quality of differentiated spermatogenic cells, so the reduction in testicular weight may be due to a decreased density of germ cells and mature sperm cells. ${ }^{37}$ Moreover, excessive MSG may aggravate the apoptosis of testicular cells. Glutamate is the final product of MSG metabolism. High levels of cyclic glutamate will affect the tricarboxylic acid cycle (TCA) and eventually increase $\alpha$-ketoglutarate dehydrogenase activity. The production of reactive oxygen species and the increased oxidative stress will result in cell apoptosis. ${ }^{38}$ In addition, glutamate receptors are heavily expressed in mouse and human testes or human spermatozoa. The activation of mGlu5 receptors may produce intracellular $\mathrm{Ca}^{2+}$ waves in cells, thus activating many responses that play a fundamental role in persistence, differentiation, and cell growth. Excessive MSG will lead to severe activation of glutamate receptors. ${ }^{39}$

On the other hand, when $\mathrm{Ca}^{2+}$ in the cell increases or a large amount of calcium enters the organelles, such as endoplasmic reticulum, nucleus, and mitochondria, 
calcium-dependent enzymes such as protease and endonuclease (caspases) become active and provide preliminary conditions for apoptosis. ${ }^{40}$ In our experiment, compared with the NC60 group, the MSG group showed a decrease in testicular weight and testicular index, a decrease in the number of spermatocytes and spermatozoa in testicular sections, a decrease in the JS score, and an increase in the apoptosis index. Compared with the MSG60 group, the weight of the testis in the MSG90 group increased slightly, but there was no significant difference in the number of spermatocytes and sperm in the testicular slices, the possible cause is the proliferation of the testicular interstitium. Therefore, our results demonstrate that MSG can cause reproductive toxicity in male mice, and this reproductive toxicity cannot be relieved spontaneously.

\section{Conclusion}

Monosodium glutamate can cause GnRH damage, neuroendocrine disorders, decreased FSH, LH, and T levels, testicular spermatogenesis damage, and increased apoptotic cells, which do not improve naturally with time. MSG is a main flavor enhancer, which is widely used in food processing and cooking. The widely use of this kind of food flavor enhancer may have adverse effects on the elderly, infants and some people with brain-blood barrier dysfunction. Studies on the harmfulness of MSG mainly focus on rodents and primates. Further research is needed to develop appropriate management policies and clear dosage for people use.

\section{Abbreviations}

MSG, monosodium glutamate; FSH, follicle stimulating hormone; LH, luteinizing hormone; GnRH, Gonadotropinreleasing hormone; T, testosterone; NC60, 60-day-old mice in normal control group; MSG60, 60-day-old mice in monosodium glutamate group; MSG90, 90-day-old mice in monosodium glutamate group; PPARs, peroxisome proliferator-activated receptors.

\section{Ethics Approval and Consent to Participate}

All procedures on animals followed Guideline for work on experimental animals approved by Ethic Committee of Faculty of Binzhou Medical University (No:2018-G005-01).

\section{Acknowledgments}

We are particularly grateful to all the people who have given us help on our article.

\section{Funding}

The present study was supported by the Medical Science and Technology development Program of Shandong Province (grant no. 2011QZ002 to Q. C. Li) and Shandong Natural Science Foundation (grant no. ZR2017LH013 to H. L. Sun).

\section{Disclosure}

The authors declare that they have no competing interests.

\section{References}

1. Fernstrom JD. Monosodium glutamate in the diet does not raise brain glutamate concentrations or disrupt brain functions. Ann Nutr Metab. 2018;73(Suppl 5):43-52. doi:10.1159/000494782

2. Vorhees CV. A test of dietary monosodium glutamate developmental neurotoxicity in rats: a reappraisal. Ann Nutr Metab. 2018;73(Suppl 5):36-42. doi:10.1159/000494781

3. Kwok RH. Chinese-restaurant syndrome. N Engl J Med. 1968;278 (14):796.

4. Samuels A. The toxicity/safety of processed free glutamic acid (MSG): a study in suppression of information. Account Res. 1999;6 (4):259-310. doi:10.1080/08989629908573933

5. Bojanić V, Bojanić Z, Najman S, et al. Diltiazem prevention of toxic effects of monosodium glutamate on ovaries in rats. Gen Physiol Biophys. 2009;28 Spec No:149-154.

6. Gilbert A, Vidal XE, Estevez R, Cohen-Salmon M, Boulay AC. Postnatal development of the astrocyte perivascular MLC1/ GlialCAM complex defines a temporal window for the gliovascular unit maturation. Brain Struct Funct. 2019;224(3):1267-1278. doi:10.1007/s00429-019-01832-w

7. Erdö F, Krajcsi P. Age-related functional and expressional changes in efflux pathways at the blood-brain barrier. Front Aging Neurosci. 2019;11:196. doi:10.3389/fnagi.2019.00196

8. Starr JM, Wardlaw J, Ferguson K, MacLullich A, Deary IJ, Marshall I. Increased blood-brain barrier permeability in type II diabetes demonstrated by gadolinium magnetic resonance imaging. J Neurol Neurosurg Psychiatry. 2003;74(1):70-76. doi:10.1136/jnnp.74.1.70

9. Tamaki K, Sadoshima S, Heistad DD. Increased susceptibility to osmotic disruption of the blood-brain barrier in chronic hypertension. Hypertension. 1984;6(5):633-638. doi:10.1161/01. HYP.6.5.633

10. Kozler P, Sobek O, Pokorny J. Biochemical manifestations of the nervous tissue degradation after the blood-brain barrier opening or water intoxication in rats. Neuro Endocrinol Lett. 2016;37 (2):114-120.

11. Zhou Y, Peng Z, Seven ES, Leblanc RM. Crossing the blood-brain barrier with nanoparticles. J Control Release. 2018;270:290-303. doi:10.1016/j.jconrel.2017.12.015

12. Al-Sarraf H, Philip L. Increased brain uptake and CSF clearance of 14C-glutamate in spontaneously hypertensive rats. Brain Res. 2003;994(2):181-187. doi:10.1016/j.brainres.2003.09.034

13. Fatemeh RA, Raheleh B, Nasibeh G, Mehdi J, Mohammad RN, Mohammad S. Effects of monosodium glutamate on apoptosis of germ cells in testicular tissue of adult rat: an experimental study. Int $j$ Reproductive Biomed. 2019;17(4):8.

14. Nemeroff CB, Konkol RJ, Bissette G, et al. Analysis of the disruption in hypothalamic-pituitary regulation in rats treated neonatally with monosodium L-glutamate (MSG): evidence for the involvement of tuberoinfundibular cholinergic and dopaminergic systems in neuroendocrine regulation. Endocrinology. 1977;101(2):613-622. doi:10.1210/endo-101-2-613 
15. Han SY, Kane G, Cheong I, Herbison AE. Characterization of GnRH Pulse Generator Activity in Male Mice Using GCaMP Fiber Photometry. Endocrinology. 2019;160(3):557-567. doi:10.1210/ en.2018-01047

16. Saadi H, Shan Y, Marazziti D, Wray S. GPR37 signaling modulates migration of olfactory ensheathing cells and gonadotropin releasing hormone cells in mice. Front Cell Neurosci. 2019;13:200. doi:10.3389/fncel.2019.00200

17. Littlejohn BP, Roberts MC, Bedenbaugh MN, et al. Evaluation of the influence of prenatal transportation stress on GnRH-stimulated luteinizing hormone and testosterone secretion in sexually mature Brahman bulls. J Anim Sci. 2017;95(1):129-138. doi:10.2527/jas.2016.0445

18. Zheng J, Mao J, Xu H, et al. Pulsatile GnRH therapy may restore hypothalamus-pituitary-testis axis function in patients with congenital combined pituitary hormone deficiency: a prospective, self-controlled trial. J Clin Endocrinol Metab. 2017;102(7):2291-2300. doi:10.1210/ jc. 2016-3990

19. Schäfer-Somi S, Kaya D, Sözmen M, Kaya S, Aslan S. Pre-pubertal treatment with a GnRH agonist in bitches-Effect on the uterus and hormone receptor expression. Reprod Domest Anim. 2018;53(Suppl 3):103-109. doi:10.1111/rda.13337

20. Marshall TM, Dardia GP, Colvin KL, Nevin R, Macrellis J. Neurotoxicity Associated with Traumatic Brain Injury, Blast, Chemical, Heavy Metal and Quinoline Drug Exposure. Altern Ther Health Med. 2019;25(1):28-34.

21. Olivares-Bañuelos TN, Martínez-Hernández I, Hernández-Kelly LC, Chi-Castañeda D, Vega L, Ortega A. The neurotoxin diethyl dithiophosphate impairs glutamate transport in cultured Bergmann glia cells. Neurochem Int. 2019;123:77-84. doi:10.1016/j. neuint.2018.06.004

22. Perelló M, Moreno G, Camihort G, et al. Nature of changes in adrenocortical function in chronic hyperleptinemic female rats. Endocrine. 2004;24(2):167-175. doi:10.1385/ENDO:24:2:167

23. Moreno G, Perelló M, Gaillard RC, Spinedi E. Orexin a stimulates hypothalamic-pituitary-adrenal (HPA) axis function, but not food intake, in the absence of full hypothalamic NPY-ergic activity. Endocrine. 2005;26(2):99-106. doi:10.1385/ENDO:26:2:099

24. Wang Z, Zhang J, Wu P, et al. Effects of oral monosodium glutamate administration on serum metabolomics of suckling piglets. J Anim Physiol Anim Nutr. 2020;104(1):269-279. doi:10.1111/jpn.13212

25. Iamsaard S, Sukhorum W, Samrid R, et al. The sensitivity of male rat reproductive organs to monosodium glutamate. Acta Med Acad. 2014;43(1):3-9. doi:10.5644/ama2006-124.94

26. Gong SL, Xia FQ, Wei J, et al. Harmful effects of MSG on function of hypothalamus-pituitary-target gland system. Biomed Environ Sci. 1995;8(4):310-317.

27. Laganà AS, Vitale SG, Nigro A, et al. Pleiotropic Actions of Peroxisome Proliferator-Activated Receptors (PPARs) in Dysregulated Metabolic Homeostasis, Inflammation and Cancer: current Evidence and Future Perspectives. Int J Mol Sci. 2016;17(7):999. doi:10.3390/ijms 17070999
28. Li PP, Shan S, Chen YT, et al. The PPARalpha/gamma dual agonist chiglitazar improves insulin resistance and dyslipidemia in MSG obese rats. $\mathrm{Br} J$ Pharmacol. 2006;148(5):610-618. doi:10.1038/sj. bjp.0706745

29. Sharma A, Kaur G. Tinospora cordifolia as a potential neuroregenerative candidate against glutamate induced excitotoxicity: an in vitro perspective. BMC Complement Altern Med. 2018;18(1):268. doi:10.1186/s12906-018-2330-6

30. Li QC, Li QF, Wang YL, Sun HL, Jiang ZY. Arcuate nucleus neurons are not essential for the preprandial peak in plasma ghrelin after neonatal monosodium glutamate treatment. Int J Mol Med. 2018;41 (3):1635-1642. doi:10.3892/ijmm.2018.3365

31. Garattini S. Glutamic acid, twenty years later. J Nutr. 2000;130(4S Suppl):901S-9S. doi:10.1093/jn/130.4.901S

32. Sheldon AL, Robinson MB. The role of glutamate transporters in neurodegenerative diseases and potential opportunities for intervention. Neurochem Int. 2007;51(6-7):333-355.

33. Greene JG, Greenamyre JT. Bioenergetics and glutamate excitotoxicity. Prog Neurobiol. 1996;48(6):613-634. doi:10.1016/ 0301-0082(96)00006-8

34. Onaolapo AY, Odetunde I, Akintola AS, et al. Dietary composition modulates impact of food-added monosodium glutamate on behaviour, metabolic status and cerebral cortical morphology in mice. Biomed Pharmacother. 2019;109:417-428. doi:10.1016/j.biopha.2018.10.172

35. Araujo TR, Freitas IN, Vettorazzi JF, et al. Benefits of L-alanine or L-arginine supplementation against adiposity and glucose intolerance in monosodium glutamate-induced obesity. Eur J Nutr. 2017;56 (6):2069-2080. doi:10.1007/s00394-016-1245-6

36. Nemeroff CB, Lamartiniere CA, Mason GA, Squibb RE, Hong JS, Bondy SC. Marked reduction in gonadal steroid hormone levels in rats treated neonatally with monosodium L-glutamate: further evidence for disruption of hypothalamic-pituitary-gonadal axis regulation. Neuroendocrinology. 1981;33(5):265-267. doi:10.1159/000123243

37. Michael B, Yano B, Sellers RS, et al. Evaluation of organ weights for rodent and non-rodent toxicity studies: a review of regulatory guidelines and a survey of current practices. Toxicol Pathol. 2007;35 (5):742-750. doi:10.1080/01926230701595292

38. Takarada T, Hinoi E, Balcar VJ, Taniura H, Yoneda Y. Possible expression of functional glutamate transporters in the rat testis. J Endocrinol. 2004;181(2):233-244. doi:10.1677/joe.0.1810233

39. Sharma A. Monosodium glutamate-induced oxidative kidney damage and possible mechanisms: a mini-review. J Biomed Sci. 2015;22:93. doi:10.1186/s12929-015-0192-5

40. Tan S, Schubert D, Maher P. Oxytosis: a novel form of programmed cell death. Curr Top Med Chem. 2001;1(6):497-506. doi:10.2174/ 1568026013394741

\section{Publish your work in this journal}

Drug Design, Development and Therapy is an international, peerreviewed open-access journal that spans the spectrum of drug design and development through to clinical applications. Clinical outcomes, patient safety, and programs for the development and effective, safe, and sustained use of medicines are a feature of the journal, which has also been accepted for indexing on PubMed Central. The manuscript management system is completely online and includes a very quick and fair peer-review system, which is all easy to use. Visit http://www. dovepress.com/testimonials.php to read real quotes from published authors. 